\title{
KETERAMPILAN BERPIKIR KREATIF SISWA MENGGUNAKAN MODEL PBL (Problem Based Learning) DENGAN PENDEKATAN STEM PADA MATERI VEKTOR DI KELAS X MIPA 4 SMA NEGERI 2 JEMBER
}

\author{
${ }^{1)}$ Mardiyah Sari Dewi, ${ }^{1)}$ Albertus Djoko Lesmono, ${ }^{2)}$ Hadiyanto, ${ }^{2)}$ Arif \\ Harimukti \\ ${ }^{1)}$ Program Studi Pendidikan Fisika FKIP Universitas Jember \\ ${ }^{2)}$ SMA NEGERI 2 Jember \\ Email: mardiyahsaridewi@gmail.com
}

\begin{abstract}
This study discusses how students think about vector material through PBL (Problem Based Learning) models using STEM (Science, Technology, Engineering, and Mathematics). The method used in this study uses qualitative descriptive research. The subjects of this study were students of grade X MIPA 4 SMA Negeri 2 Jember with a total of 35 students. The instruments of collecting data in this study consisted of student worksheets and questionnaires to measure students' creative thinking skills. Student worksheets are provided using STEM (Science, Technology, Engineering, and Mathematics) which have been adapted to the 2013 curriculum that directs students to be actively involved in learning activities. fluency, flexibility, elaboration and originality which contains 6 indicators. The results of the questionnaire data were analyzed based on its indicators, namely for the first indicator getting a percentage of creative thinking skills by $74 \%$, the second indicator by $78 \%$, the third indicator by $74 \%$, the percentage indicator by $69 \%$, the percentage indicator by $74 \%$, and for the sixth indicator by $70 \%$. The number of students who reached the criteria was quite creative there were 33 students with a percentage of $94 \%$. Based on the results of data analysis obtained, students think a high percentage. The PBL (Problem Based Learning) model using STEM (Science, Technology, Engineering, and Mathematics) on vector material has good implications and supports an effective and enjoyable learning process for students.
\end{abstract}

Keywords: creative thinking skills, problem based learning, STEM, vector.

\section{PENDAHULUAN}

Fisika adalah bagian dalam Sains yang berasal dari fenomena alam. Dalam kegiatan belajar fisika, keaktifan siswa sangat diperlukan. Keaktifan yang ada pada kegiatan belajar fisika terletak pada dua segi, yang pertama yaitu aktif dalam bertindak (hands activity) dan yang kedua yaitu aktif dalam berpikir (minds activity) (NRC, 1996). Mims (2003) menjelaskan bahwa siswa akan aktif jika siswa dapat menghubungkan antara pengetahuan baru dengan pemahaman awal yang mereka miliki. Namun untuk menghubungkan pengetahuan baru dan pengetahuan awal dalam pembelajaran fisika tidaklah mudah.

Kurikulum 2013 mengamanatkan untuk menggunakan pendekatan ilmiah dalam kegiatan pembelajaran. Pendekatan ilmiah diyakini sebagai perkembangan dan pengembangan sikap keterampilan, dan pengetahuan siswa. Metode ilmiah merujuk pada teknik-teknik investigasi atas 
fenomena atau gejala, memperoleh pengetahuan baru, atau mengoreksi dan memadukan pengetahuan sebelumnya. Pembelajaran scientific tidak hanya memandang hasil belajar sebagai hasil akhir, namum lebih menekankan pada proses pembelajara. Dalam proses pembelajaran siswa dituntut agar berperan aktif terutama dalam kegiatan penemuan, sedangkan guru yang semula bertindak sebagai sumber belajar beralih fungsi menjadi seorang fasilitator kegiatan pembelajaran yang berperan mengarahkan (membimbing) siswa untuk memecahkan permasalahan yang dihadapi dalam proses kegiatan belajar atau menemukan sendiri konsepkonsep yang sedang dipelajari. (Mendikbud, 2013).

Hasil studi The Programme for International Student Assessment (PISA) 2014, Indonesia berada di peringkat ke-64 dari 65 negara dengan skor 382 dari skor rata-rata 501 (OECD, 2014). Hal tersebut didukung dengan hasil penelitian lanjutan yang dilakukan oleh Permanasari (2016) terhadap data PISA menunjukkan bahwa kemampuan memecahkan masalah anak Indonesia sangat rendah, jauh dibandingkan dengan negaranegara seperti Malaysia, Thailand, atau Filipina.

Keterampilan berpikir kreatif penting untuk dimiliki peserta didik dalam memecahkan permasalahan. Hal ini dikarenakan keterampilan berpikir kreatif adalah keterampilan dasar yang harus dikembangkan di sekolah (Ozdas \& Veli, 2017). Hal tersebut didukung oleh hasil penelitian dari Sambada (2012) yang menyatakan bahwa semakin tinggi kreativitas yang dimiliki siswa semakin tinggi pula kemampuan untuk memecahkan masalah dalam kegiatan pembelajaran fisika. Sesuai dengan tujuan dari Depdiknas (2008), yakni menggali kreativitas siswa yang bertujuan untuk menghasilkan lulusan yang memiliki kemampuan sesuai dengan standar kompetensi lulusan, diperlukan pengembangan pembelajaran untuk setiap kompetensi secara sistematis, terpadu, dan tuntas.

Pengembangan kreativitas siswa bergantung pada guru dalam mengetahui bagaimana kreativitas tersebut dikembangkan (Bayindir \& Inan, 2008). Kebanyakan guru masih menerapkan pembelajaran yang bersifat konvensional, dimana proses pembelajaran pada umumnya hanya melatih proses berpikir konvergen, sehingga bila dihadapkan suatu permasalahan, siswa akan kesulitan memecahkan masalah tersebut secara kreatif (Munandar, 2001). Seorang guru perlu menggunakan suatu pendekatan pembelajaran yang dapat melatih keterampilan berpikir kreatif siswa. Salah satu pendekatan pembelajaran yang dapat digunakan untuk melatih keterampilan berpikir kreatif adalah pendekatan pembelajaran STEM (Beers, 2011).

STEM dapat berkembang apabila dikaitkan dengan lingkungan, sehingga terwujud sebuah pembelajaran yang menghadirkan dunia nyata yang dialami siswa dalam kehidupan seharihari (Subramaniam et al, 2012). Hal ini berarti melalui pendekatan STEM siswa tidak hanya sekedar menghafal konsep saja, tetapi lebih kepada bagaimana siswa mengerti dan memahami konsep-konsep sains dan kaitanya dalam kehidupan sehari-hari. Selain penggunaan pendekatan pembelajaran yang tepat, penggunaan bahan ajar pun harus sesuai agar 
keterampilan berpikir siswa dapat terlatih. Bahan ajar memainkan peran penting dalam memastikan efektivitas kegiatan belajar mengajar, salah satunya adalah lembar kerja siswa (LKS) (Kaymakci, 2012).

Berikut Tabel 1 merupakan beberapa aspek dan indikator keterampilan berpikir kreatif siswa:

Tabel 1. Aspek dan indikator keterampilan berpikir kreatif siswa.

\begin{tabular}{cll}
\hline No & Aspek & Indikator \\
\hline 1 & Kelancaran & $\begin{array}{l}\text { Mengajukan } \\
\text { pertanyaan }\end{array}$ \\
\hline 2 & Keluwesan & $\begin{array}{l}\text { Mempertimbangkan } \\
\text { informasi baru }\end{array}$ \\
\hline 3 & Elaborasi & $\begin{array}{l}\text { Membangun } \\
\text { keterkaitan }\end{array}$ \\
\cline { 3 - 3 } & & $\begin{array}{l}\text { Menghubungkan } \\
\text { berbagai hal dengan } \\
\text { bebas }\end{array}$ \\
\hline 5 & Keaslian & $\begin{array}{l}\text { Menerapkan } \\
\text { imajinasi }\end{array}$ \\
\cline { 3 - 3 } & & $\begin{array}{l}\text { Mendengarkan } \\
\text { intuisi }\end{array}$ \\
\hline
\end{tabular}

Dengan demikian, hasil penelitian ini membahas tentang keterampilan berpikir kretaif siswa menggunakan model PBL dengan pendekatan STEM pada materi vektor di SMA.

\section{METODE PENELITIAN}

Penelitian ini menggunakan pendekatan kualitatif dan dianalisis secara deskriptif. Penelitian deskriptif digunakan untuk menggambarkan hasil pembelajaran terutama pada indikator berpikir kreatif siswa. Penelitian ini dilakukan pada kelas $\mathrm{X}$ di SMAN 2 JEMBER. Subjek dalam penelitian ini adalah kelas X MIPA 4 yang terdiri dari 35 siswa pada tahun pelajaran 2019/2020.

Data yang dikumpulkan pada penelitian ini merupakan data kualitatif yang dikumpulkan menggunakan angket yang disebar kepada siswa setelah melakukan pembelajaran menggunakan STEM (Science, Technology, Engineering And Mathematics).

Pada penelitian ini menggunakan kuesioner untuk mengetahui kondisi berpikir kreatif siswa. Kuesioner merupakan teknik pengumpulan data efisiensi dan dilakukan dengan cara memberi seperangkat pernytaaan tertulis kepada responden untuk menciptakan kondisi yang baik, sehingga responden dengan sukarela memmberikan data objektif dan cepat. Kuesioner telah dibagikan kepada siswa kelas $\mathrm{X}$ untuk diisi sesuai dengan kondisi yang sebenar benarnya. Dalam penelitian ini peneliti membuat 26 pernyataan kuesioner.

Penilaian setiap komponen pada kuesioner menggunakan skala likert. Berikut pedoman penskoran kuesioner sebagaimana ditunjukkan pada Tabel 2 berikut.

Tabel 2. Pedoman penskoran kuesioner.

\begin{tabular}{|c|c|}
\hline Favorable & Unvaforable \\
\hline Sangat Setuju & 1 \\
\hline Setuju & 2 \\
\hline Tidak Setuju & 3 \\
\hline $\begin{array}{lll}\text { Sangat } & \text { Tidak } & 1 \\
\text { Setuju } & & 1 \\
\end{array}$ & 4 \\
\hline $\begin{array}{l}\text { Pada tabel mer } \\
\text { dalam skala Likert yas } \\
\text { adalah skor sangat Setuj } \\
\text { (S), Tidak Setuju (TS), } \\
\text { Setuju (STS) dan denga } \\
\text { jika pernyataan terseb } \\
\text { (pernytaan positif) maka } \\
\text { nilai (4,3,2,1) dan untu } \\
\text { (Pernyataan negatif) men } \\
(1,2,3,4) \text {. Penilaian in }\end{array}$ & $\begin{array}{l}\text { pakan skor } \\
\text { g digunakan } \\
(\mathrm{SS}), \text { Setuju } \\
\text { sangat Tidak } \\
\text { perhitungan } \\
\text { it favorable } \\
\text { mendapatkan } \\
\text { unfavorable } \\
\text { lapatkan nilai } \\
\text { digunakan }\end{array}$ \\
\hline
\end{tabular}


untuk mendapatkan data berpikir kreatif siswa kelas X SMAN 2 Jember.

$$
\text { Precentage }=\frac{\sum n}{\sum N} \times 100 \%
$$

$\sum \mathrm{n}=$ jumlah skor siswa

$\sum \mathrm{N}=$ jumlah skor maksimum

Data berpikir kreatif siswa yang didapat direkap dijadikan nilai dari berpikir kreatif siswa dengan suatu kriteria atau patokan sebagai dasar acuan yaitu ditunjukkan pada Tabel 3 berikut:

Tabel 3. Presentase kriteria berpikir kreatif siswa.

\begin{tabular}{cl} 
& siswa. \\
\hline Presentase & Kriteria \\
\hline $90-100 \%$ & Sangat Kreatif \\
\hline $80-89 \%$ & Kreatif \\
\hline $65-79 \%$ & Cukup Kreatif \\
\hline $55-64 \%$ & Kurang Kreatif \\
\hline$<55 \%$ & Sangat Kurang Kreatif \\
\hline
\end{tabular}

\section{HASIL DAN PEMBAHASAN}

Penelitian ini menggunakan instrumen lembar kerja siswa dan angket untuk mengukur tingkat keterampilan berpikir kreatif siswa pada materi vektor. Lembar kerja siswa yang diberikan menggunakan pendekatan STEM (science, Technology, Engineering and Mathematics) yang telah disesuaikan dengan kurikulum 2013.

Adapun total responden yang mengikuti kegiatan pembelajaran adalah 35 orang. Terdapat beberapa indikator yang digunakan untuk tolak ukur keterampilan berpikir kreatif siswa ada 6 indikator diatarannya adalah mengajukan pertanyaan, mempertimbangkan informasi baru, membangun keterkaitan, menghubungkan berbagai hal dengan bebas, menerapkan imajinasi, dan mendengarkan intuisi. Kemudian data dianalisis menggunakan indikator tersebut. Tingkat keterampilan berpikir kreatif siswa dianalisis tiap indicator sebagaimana ditunjukkan pada Tabel 4 berikut.

Tabel 4. Presentase rata rata berpikir kreatif siswa.

\begin{tabular}{|c|c|c|c|c|c|c|}
\hline & \multicolumn{6}{|c|}{ Presentase\% } \\
\hline & $\mathrm{a}$ & $\mathrm{b}$ & $\mathrm{C}$ & $\mathrm{d}$ & $\mathrm{e}$ & $\mathrm{f}$ \\
\hline $\begin{array}{c}\text { Presentase } \\
\text { rata rata }\end{array}$ & $74 \%$ & $78 \%$ & $74 \%$ & $69 \%$ & $74 \%$ & $70 \%$ \\
\hline \multicolumn{7}{|c|}{$\begin{array}{ll}\mathrm{a}=\text { indikator mengajukan pertanyaan } & \text { indikator ketiga sebesar } 74 \% \text {, indikator } \\
\mathrm{b}=\text { mempertimbangkan informasi baru } & \text { sebesar } 74 \%, \text { dan untuk indikator } \\
\mathrm{c}=\text { membangun keterkaitan } & \text { keenam sebesar } 70 \% . \text { Berikut Tabel } 5 \\
\mathrm{~d}=\text { menghubungkan berbagai hal } & \text { hasil presentase berpikir kreatif siswa. } \\
\text { dengan bebas } & \text { Tabel } 5 . \text { Hasil presentase berpikir kreatifsiswa. }\end{array}$} \\
\hline \multirow{6}{*}{\multicolumn{4}{|c|}{$\begin{array}{l}\mathrm{e}=\text { menerapkan imajinasi } \\
\mathrm{f}=\text { mendengarkan intuisi } \\
\text { Hasil data kuesioner dianalisis menurut } \\
\text { indikatornya yaitu untuk indikator } \\
\text { pertama mendapatkan presentase } \\
\text { ketrampilan berpikir kreatif sebesar } \\
74 \% \text {, indikator kedua sebesar } 78 \% \text {, }\end{array}$}} & Kategori & $\begin{array}{l}\text { Jumlah } \\
\text { siswa }\end{array}$ & Presentase \\
\hline & & & & Sangat kreatif & 0 & $0 \%$ \\
\hline & & & & kreatif & 3 & $8 \%$ \\
\hline & & & & Cukup kreatif & 30 & $86 \%$ \\
\hline & & & & Kurang kreatif & 2 & $6 \%$ \\
\hline & & & & $\begin{array}{l}\text { Sangat kurang } \\
\text { kreatif }\end{array}$ & 0 & $0 \%$ \\
\hline
\end{tabular}


Jumlah siswa yang mencapai kriteria minimal cukup kreatif ada 33 siswa dengan presentase $94 \%$. Berdasarkan hasil analisis data diperoleh bahwa keterampilan berpikir kreatif siswa menunjukkan presentase yang tinggi.

Dengan memberikan lembar kerja siswa menggunakan pendekatan STEM (science, Technology, Engineering and Mathematics) siswa mampu menggunakan ilmu pengetahuan yang dimiliki pada materi vektor untuk mengajukan beberapa pertanyaan. Dengan dilakukannya pembelajaran ini siswa dituntut untuk berdiskusi yang akan menimbulkan informasi baru dan siswa dapat mempertimbangkan informasi yang didapat. Informasi baru yang didapat pada saat pembelajaran berlangsung siswa mampu menghubungkan keterkaitan dengan materi atau juga dapat menghubungkan dengan bebas. Dalam pembelajaran menggunakan pendekatan STEM (science, Technology, Engineering and Mathematics) ini juga siswa dapat mengembangkan imajinasi karena diberi kebebasan untuk berkarya dan juga dapat mendengarkan intuisi.

\section{SIMPULAN DAN SARAN}

Berdasarkan hasil analisis data yang diambil di kelas $\mathrm{X}$ MIPA 4 SMAN 2 Jember dapat disimpulkan bahwa keterampilan berpikir kreatif siswa menunjukkan presentase yang tinggi. Dalam hal ini dapat menunjukkan bahwa keterampilan berpikir kreatif siswa melalui model PBL (Problem Based Learning) dengan pendekatan STEM (Science, Technology, Engineering, and Mathematics) pada materi vektor memiliki implikasi yang baik dan mendukung proses kegiatan pembelajaran yang efektif sekaligus menyenangkan bagi siswa.

\section{DAFTAR PUSTAKA}

Bayindir, N., \& Inan, H. Z. 2008. Theory into practice: Examination of teacher practices in supporting children's creativity and creative thinking. Ozean Journal of Social Science, 1(1).

Beers, S. 2011. 21st Century Skills : Preparing Students For Their Future. Diakses dari http://www.yinghuaacademy.org/ wpcontent/uploads/2014/10/21st_ce ntury_skills.pdf

Depdiknas. 2008. Panduan Pengembangan Bahan Ajar. Direktorat Pembinaan Sekolah Menengah Atas.

Kementrian Pendidikan dan Kebudayaan. 2013. Materi Pelatihan Guru: Implementasi Kurikulum 2013 SMA/MA, SMK/MAK Matematika. Jakarta: Kemdikbud.

Mims, Clif. 2003. Authentic Learning: A Practical Introduction \& Guide for Implementation. A Middle School Computer Technologies Journal. 6 (1), Winter 2003, ISSN 10979778

Munandar, Utami. 2001. Mengembangakan Bakat dan Kreatifitas Anak Sekolah. Jakarta: PT. Gramedia Widiasarana. 
National Research Council. 1996. National Science Education Standard. Washington DC: National Academy Press.

OECD. 2014. PISA 2012 Results in Focus: What 15- year-olds know and what they can do whit what they know.

Ozdas, Faysal. 2017. A Thematicbased Meta Analytic Study Regarding the Effect of Creativity on Academic Success and Learning Retention. Journal of Education and Training Studies. 5 (3): 53
Permanasari, A. 2016. STEM Education: Inovasi dalam Pembelajaran Sains. Prosiding Seminar Nasional Pendidikan Sains. Surakarta: Universitas Sebelas Maret.

Sambada, D. 2012. Peranan Kreativitas Siswa Terhadap Kemampuan memecahkan Masalah Fisika dalam Pembelajaran Kontekstual. Jurnal Penelitian Fisika dan Aplikasinya, 2 (2): 37-47. 